\title{
Correction to: Performance
} of an ultra-sensitive Plasmodium falciparum HRP2-based rapid diagnostic test with recombinant HRP2, culture parasites, and archived whole blood samples

Smita Das ${ }^{*}{ }^{\dagger}$, Roger B. Peck ${ }^{\dagger}$, Rebecca Barney, Ihn Kyung Jang, Maria Kahn, Meilin Zhu and Gonzalo J. Domingo

\section{Correction to: Malar J (2018) 17:118}

https://doi.org/10.1186/s12936-018-2268-7

Following publication of the original article [1], the authors flagged an error concerning a reference to a product in the Methods section.

The article states "Diluent lot number: 05BDDA145, Manufacture date: 2015.02.25, Expiry date: 2017.02.25".

However, it should read: "Diluent lot number: 05BDDA145, Manufacture date: 2016.02.25, Expiry date: 2017.02.24".

The author apologizes for this error.

The original article can be found online at https://doi.org/10.1186/s1293 6-018-2268-7.

\section{Publisher's Note}

Springer Nature remains neutral with regard to jurisdictional claims in published maps and institutional affiliations.

Published online: 04 February 2019

Reference

1. Das S, Peck RB, Barney R, Jang IK, Kahn M, Zhu M, Domingo GJ. Performance of an ultra-sensitive Plasmodium falciparum HRP2-based rapid diagnostic test with recombinant HRP2, culture parasites, and archived whole blood samples. Malar J. 2018;17:118. https://doi.org/10.1186/s1293 6-018-2268-7. 